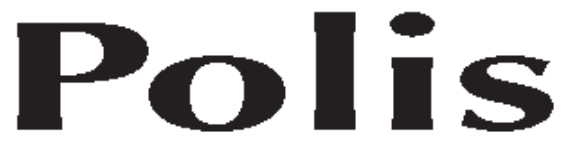

\title{
Nietzsche y su visión del derecho penal ${ }^{*}$
}

\section{Edison Carrasco Jiménez ${ }^{* *}$}

\begin{abstract}
Resumen: El trabajo del autor analiza el pensamiento penal del filósofo alemán Friedrich Nietzsche, de cómo las normas penales poseen un sustento moral, y cómo la pena es una de las formas de grabar con fuego los deberes que impone la moral. Además, Nietzsche arroja sus sospechas sobre el contrato social como forma de constituir la sociedad y cuestiona las bases de la relación Estado-delincuente bajo el pacto social. Sin embargo, fuera de negar la idea de dicho pacto como creador del Estado, considera propositivamente, una forma de Estado y un derecho penal diverso. Esto representa, a juicio del autor, un momento dialéctico positivo. Señala el autor en adición, cómo el pensamiento nietzscheano es propicio en la reflexión latinoamericana; en primer lugar, por fijar el contenido de lo europeo con mayor precisión, para que el pensamiento latinoamericano sepa de qué habrá de diferenciarse con aquel; en segundo lugar, por la aplicación de la genealogía de la penalidad a la historia nuestras propias instituciones.
\end{abstract}

Palabras Clave: Nietzsche, Filosofía del Derecho, Filosofía Penal, Derecho Penal, Pensamiento Latinoamericano.

\section{Nietzsche and his vision on penal thought}

Abstract: The work of the author analyzes the penal thought of the German philosopher Friedrich Nietzsche, of how the penal norms possess a moral background, and how punishment is one of the ways to mark an incandescent memory of the duties morality imposes. Besides, Nietzsche sets out his suspicion on the social contract as a way to constitute society and questions the bases of the State-delinquent relationship under the social contract. Nevertheless, in spite of denying the idea of such pact as the creator of the State, he considers, as a proposal, a different form of State and of criminal law. This represents, in the opinion of the author, a positive dialectical moment, who indicates, in addition, how the nietzschean thought is favorable to Latin-American analysis; first by setting the content of European thought with greater precision, so that Latin-American thought can know about from what to differentiate; and second, through the application of the genealogy of punishment to the history of our own institutions.

Key words: Nietzsche, Philosophy of Law, Penal Philosophy, Criminal Law, Latinamerican thought.

Recibido: 16.06 .08

Aceptado: 08.10 .08

$* * *$

\footnotetext{
* Para Nietzsche utilizaremos la traducción de Sergio Albano en Nietzsche, Friedrich (2003), Genealogía de la moral, Gradifco SRL, Buenos Aires, Argentina; y la traducción de Anibal Froufe y Carlos Vergara en Nietzsche, Friedrich. (1969), Obras Inmortales, Ediciones Distribuciones, Madrid, España.

${ }^{* *}$ Universidad de Salamanca, Salamanca, España. Email: ecarrasj@ hotmail.com
} 


\section{Exposición}

La reflexión en materia penal, ha sido centrada específicamente en ciertos discursos considerados "oficiales", entre los que destaca el pensamiento ilustrado. Desde ahí arrancan las concepciones modernas acerca del sistema penal europeo, y en gran parte, las legislaciones actuales sobre la materia, en el mundo occidental. Sin embargo, no todo el pensamiento penal tiene por canónicas las consideraciones penales ilustradas ni las concepciones clásicas sobre el derecho penal. Uno de estos pensamientos es el de Friedrich Nietzsche (1844-1900).

El filólogo y filósofo alemán, Friedrich Nietzsche, ha sido considerado, sin duda alguna, un pensador relevante en el campo de la metafísica y de la filosofía en general. Sin embargo, no ha corrido la misma suerte dentro del campo del derecho, menos aún en el derecho penal, donde no puede decirse que cuantitativamente los estudios sean abundantes, y aquellos direccionados hacia la filosofía jurídico-política, en algunos casos han sido afectados por deformaciones partidarias e ideológicas, sea por la incomprensión de su pensamiento $^{1}$, sea por la segmentación y manipulación de sus textos por los herederos materiales. Una palabra sobre lo dicho. A Nietzsche siempre se le ha reclamado haber sido antisemita y precursor del nacionalsocialismo, y como estas reclamaciones, otras, siempre "sujeto a las interpretaciones más opuestas y aberrantes" (Quintano Ripollés 1957:175), donde en el hoy, si no directamente, se vuelve a plantear el tema de haber tenido una cuota de responsabilidad por su pensamiento "profundamente antidemocrático" (Moraleja 2001:9-10) ${ }^{2}$. Sin embargo, fuera de interpretaciones superficiales y antojadizas, a malentendidos de su obra de "modo banal" (Fink 1966:9) y a la "actitud ordinaria de las interpretaciones de Nietzsche" (Fink 1966:13), mucho de sus textos posteriores fueron crudamente instrumentalizados por su hermana, Elizabeth Förster, y aún conscientemente

\footnotetext{
${ }^{1}$ Sobre lo dicho ya Nietzsche en su época señalaba las incomprensiones en la lectura de sus libros (carta a su editor Peter Gast y a su madre, 18 de julio de 1887 y 3 de octubre de 1887, en Nietzsche (1989) Correspondencia, trans. Felipe González Vicen, Ediciones Aguilar, Barcelona, pp. 406 y 408). Así afirma González Vicen: "Su pensamiento central y los supuestos en que descansa permanecen tan desconocidos como en la época de mayor soledad y de más radical incomprensión, y el "entendimiento" de Nietzsche se centra en el vehículo deslumbrante en que aquel pensamiento había buscado forma expresiva. Los giros brillantes, las formulaciones y perspectivas insólitas son extraídos del movimiento dialéctico del sistema, considerados "en sî" y utilizados para instrumentar una concepción del mundo y de la vida fundamentalmente contraria a aquella a cuyo servicio había puesto Nietzsche su obra. Los mismos contra los que edificó su vida son ahora los albaceas y apologistas de su pensamiento, y puede decirse que no hay una frase de Nietzsche que no sea interpretada en un sentido opuesto al que Nietzsche le diera en el conjunto total de su filosofía" (GONZÁLES VICEN, Introducción, en Nietzsche (1989) Correspondencia, trans. Felipe González Vicen, Ediciones Aguilar, Barcelona, pp. 75-76).

${ }^{2}$ Que si por deformaciones se trata de pensamientos, el cristiano tiene "notables" deformaciones de su sentido primitivo. Sobre ello son tantos los ejemplos como desviaciones de sentido pueden existir.
} 
alterados, para fines proselitistas de corte antisemita y nacionalsocialista, que su marido detentaba como ideología. No obstante Nietzsche estar distanciado de ambas ideas, aborrecía el antisemitismo, lo cual fue motivo de divergencia con el consorte de su hermana y sus proyectos conjuntos, y una de las razones de su distanciamiento con Wagner, según lo afirmado por el propio Nietzsche. El filósofo señalaba lo siguiente en su correspondencia a su madre fechada en 1886, después de haber escrito Más allá del bien y del mal: "Lo ocurrido con S., o como se llame el antisemita de quien me escribes, me ha preocupado. Aquí lo ves tú; por causa de este tipo de personas no quise yo ir al Paraguay. Es para mí una dicha que ellos mismos se destierren voluntariamente de Europa. Pues aunque yo sea un mal alemán, como dicen, en todo caso soy un excelente europeo"(Nietzsche 1989:376). Por lo demás, si se rastrea concienzudamente el pensamiento nietzscheano se ha de encontrar profundas e irreconciliables desavenencias con todo nazismo por el intenso carácter humanista de su concepción, pensamiento nietzscheano "no solamente diverso al nazi -según Quintano Ripollés- sino diametralmente opuesto a él en lo esencial" (Quintano Ripollés 1957:176). Importante es hacer la aclaración, para poder precisar su concepción jurídico penal desprovista de prejuicios sólo surgidos de la imperfecta comprensión de su pensamiento en algunos casos, y en otros, directamente anclados en la ignorancia.

Para nosotros, lejos de ser resistido, el pensamiento penal nietzscheano ha servido de base y fundamento sobre el que han descansado los pensamientos críticos sobre la materia jurídica que señalaron años más tarde las "indagaciones" de Foucault y de criminólogos posteriores. ${ }^{3}$

Las observaciones más pródigas al derecho penal que Nietzsche brinda, las encontramos fundamentalmente en el libro "La Genealogía de la moral" (Zur genealogie der moral $),{ }^{4}$ y en un aspecto más breve y disperso, en el libro "La Voluntad de Poder". No hay en el pensador europeo, un aparente tratamiento sistemático de su pensamiento penal, al modo acostumbrado, lo cual hace reparar a Quintano Ripollés sobre esta supuesta característica. ${ }^{5}$ Los que interpretan someramente a Nietzsche y le atribuyen falta de sistematicidad, caen en una confusión. La falta de sistematicidad de Nietzsche -como ya anunciamos anteriormente- sólo es aparente. Su discurso no está configurado a través de un orden textual acostumbrado, lo cual no quiere decir que no sea un pensamiento coherente y organizado. La falta de centro textual no necesariamente significa falta de centro

\footnotetext{
${ }^{3}$ Sobre las reflexiones penales de Foucault, Vid. Carrasco Jiménez (2008) "El pensamiento penal de Michel Foucault" Revista Polis 5, http://www.revistapolis.cl/18/pens.htm.

${ }^{4}$ Este libro da las mayores luces sobre el tema del derecho penal, especialmente, a través de su Tratado Segundo, el cual nos introduce en una concepción que va a incidir posteriormente en posiciones críticas al derecho. El parágrafo de este tratado, sin duda que es decidor en la relación entre moral y derecho ("Culpa", "Mala conciencia" y similares).

${ }^{5}$ Como bien resalta Quintano Ripollés del filósofo su carácter "inorgánico" y "asistemático", pero igualmente genial (Quintano Ripollés (1957) "Ideas jurídicas de Nietzsche”, en Anuario de Filosofía del Derecho, 175194, p. 179).
} 
metodológico y falta de coherencia y lógica. Muchos textos de otros autores pueden presentarse textualmente coherentes y desordenados desde el punto de vista lógico, faltos de coherencia y metodológicamente desprovistos. Nietzsche sí presenta un sistema, sólo que su textualidad es formalmente asistemática. Asistemática en las ideas como datos, como conocimiento estadístico; sistemática en las ideas, en su desarrollo, y en la plenitud de coherencia y del uso de una metodología. ${ }^{6}$

A través de la presunta desorganización de los aforismos nietzscheanos, hemos de rastrear en sus obras, y básicamente en las señaladas, su reflexión sobre la materia criminal. Pero desprenderse por ello de su obra general so pretexto de tratar sólo su pensamiento penal, carecería de rigor y no podría aportar las luces suficientes para una omnicomprensión del pensamiento nietzscheano. Es imposible separarse de su reflexión global, donde existe una unicidad férrea. Seguir, por ende, este hilo conductor es imperioso, y no perder de vista su filosofía general, una necesidad. Sobre esto trataremos de satisfacer en lo que más se pueda y en la medida de nuestras fuerzas.

So riesgo de algún tipo de reparo, ${ }^{7}$ intentaremos efectuar una sistematización a la tratativa propuesta. Claro está, sistematicidad más bien textual de los contenidos nietzscheanos. A somero modo estructuraremos este estudio encabezándolo por el método utilizado por Nietzsche en su formulación teórica, luego señalar un marco explicativo brevísimo de su pensamiento general, para a continuación abordar su pensamiento jurídico penal.

\section{Marco general del pensamiento nietzscheano}

\section{Método genealógico ${ }^{8}$}

En cuanto al término "genealogía" y al significado utilizado por el filósofo, se deriva del libro "La genealogía de la moral", el cual Nietzsche consideraba después de "Así

\footnotetext{
${ }^{6}$ Esto se refuerza aún más, con las ideas de Vattimo, donde vislumbra la genealogía de Nietzsche, y en contraposición (según Vattimo) a Deleuze, no sólo y simplemente como un método, sino como un momento en el desarrollo de la filosofía -léase igualmente metodología- (Vattimo (1989) El sujeto y la máscara, trans. Jorge Binagui, Historia, ciencia y sociedad, Ediciones Península, Barcelona, p. 132, nota al pie $\mathrm{N}^{\circ} 2$ ).

7 Quintano Ripollés califica de "ridículo", cualquier intento de sistematización (Quintano Ripollés (1957) "Ideas jurídicas de Nietzsche”, en Anuario de Filosofía del Derecho, 175-194, p. 175).

${ }^{8}$ Entendemos tal referencia con una terminología amplia y no reduciéndola sólo a ser parte del arsenal metodológico de cualquier aproximación científica, aunque para nosotros, tampoco la excluye totalmente. En la visión de la genealogía nietzscheana acogemos así las críticas de Vattimo a Deleuze sobre un concepto genealógico nietzscheano más integrador de su filosofía vital misma (Vattimo (1989) El sujeto y la máscara, trans. Jorge Binagui, Historia, ciencia y sociedad, Ediciones Península, Barcelona).
} 
hablaba Zaratustra" y junto con "Más allá del bien y el mal", como el más importante de su producción y "de más amplia problemática" (Nietzsche 1989:426), escrito en épocas donde, y como dice Thomas Mann, el genio de Nietzsche "llegó a su vértice" (Mann 2000:99). No por nada Quintano Ripollés dice que en él se encuentra "una de las más originales interpretaciones filosóficas de la historia del Derecho penal” (Quintano Ripollés 1957:189).

La genealogía si bien es interpretación, se basa a su vez en el marco general de su filosofía, la cual, en palabras de Ricoeur, toda ella es interpretación (Ricoeur 1970). ${ }^{9}$ Según este último autor, Nietzsche, al igual que Marx y Freud -a los cuales agrupadamente llama "escuela de la sospecha" (Ricoeur 1970:32)- pretende enfocarse sobre la "conciencia falsa" (Ricoeur 1970:33). Esto es, que tanto en Nietzsche como en los citados pensadores, el punto de partida no es la duda sobre la cosa, cuestión ya propugnada algunos siglos atrás por Descartes, sino más bien la duda sobre la misma conciencia que percibe la cosa. Y allí se encuentra su novedad. Todos estos se caracterizan por cuatro cosas específicas: a) la destrucción a través de la crítica; b) la interpretación para despejar la verdad; c) mostrar la relación en el binomio oculto/mostrado o manifiesto/simulado, y finalmente; d) la utilización de métodos de desciframiento. Así tanto la genealogía, como la teoría de la ideología marxista y el análisis de las ilusiones en Freud "representan procedimientos convergentes de la desmistificación (Ricoeur 1970:34)".

La genealogía de Nietzsche, se encuentra íntimamente emparentada con el tema valórico y moral. No sólo por el propio fundamento del libro el cual le da acogida a esta metódica, sino por la íntima conexión (reconocido por el propio Nietzsche) ${ }^{10}$ con "Más allá del bien y el mal", soporte de "La genealogía de la moral".

Las visiones interpretativas sobre la conceptualización de la genealogía como método o discurso, son diversas, aunque no cuantitativamente pródigas. Dedicarnos con profusión sobre este punto, ameritaría un estudio separado. Por hoy nos contentaremos con proporcionar unas luces que, aunque débiles, nos podrán orientar en el camino de entendimiento de la genealogía nietzscheana.

Tras los pasos de la genealogía nietzscheana, Foucault (1995), señala que Nietzsche utiliza más bien una hermenéutica, una técnica de interpretación como una forma de escrutar la historia, pero de distinta forma que el historiador; pretende el estudio del origen de las cosas o de determinados acontecimientos, pero de algún modo demitificándolos. ${ }^{11}$

\footnotetext{
${ }^{9}$ El mismo Nietzsche señala: "Impregna mis escritos que el valor del mundo reside en nuestra interpretación" (Nietzsche (2006) Nihilismo: Escritos póstumos, trans. Gonçal Mayos Solsona, Ediciones Penínusla, Barcelona, p. 42).

${ }^{10}$ Carta a Jacob Burckhardt el 14 de noviembre de 1887 (Nietzsche (1989) Correspondencia, trans. Felipe González Vicen, Ediciones Aguilar, Barcelona, p. 410).

11 El pensador francés Michel Foucault, describe esta genealogía como un "acoplamiento de los conocimientos eruditos y de las memorias locales que permite la constitución de un saber histórico de la lucha y la utilización de ese saber en las tácticas actuales" como forma de "hacer entrar en juegos los saberes locales, discontinuos, descalificados, no legitimados, contra la instancia teórica unitaria que pretende filtrarlos, jerarquizarlos, ordenarlos en nombre del conocimiento verdadero y de los derechos de una ciencia que está detentada por unos pocos" (Foucault, Microfísica del poder, p. 130).
} 
Esto porque el hombre supone que las cosas en el origen eran perfectas (Foucault 1988). Sin embargo "detrás de la verdad, siempre reciente...hay la milenaria proliferación de errores" (Foucault 1988:21) y las múltiples ardides falsificaciones del sentido (Ricoeur 1970) que la genealogía nietzscheana pretende descubrir. Por su parte Deleuze afirma que la genealogía se cierne como un verdadero método que cuenta con el "elemento diferencial" (Deleuze 1986:9), que supone una toma de distancia respecto de aquello que se critica, crítica que se distancia valorativamente de su objeto y que se concibe como acción, y por ende creadora, más que simple re-acción, y por tanto, re-sentimiento. Vattimo (1989) lo atisba como un momento en la filosofía nietzscheana que conduce a la formulación final del superhombre.

La genealogía pretende poner en evidencia la llamada "verdad"-“inercia, hipótesis de donde brota el contentamiento, el menor consumo de fuerza espiritual"(Nietzsche 2006:43)-, y descubrir tras sus fauces, el origen, con el fin de reconstruirlo, con sus verdades y mentiras, tal como es, sin enmascaramientos de ningún tipo, o a lo menos manifestar la falsedad del mundo, la "invención poética" que es el mundo (Nietzsche 2006:42) que se cree con certeza vivir y ver. Nietzsche así, se centra en el herkunft, en el tronco, procedencia u origen de las cosas. La genealogía va tras el origen de los valores: buenos o malos, positivos o negativos. Es una búsqueda "desvalorada" de los valores, en una suerte de objetividad científica y desprejuiciada del origen de las cosas en sus últimos fundamentos axiológicos.

\section{Marco general de su pensamiento sobre la moralidad}

Existe en el pensador alemán una animadversión hacia la racionalidad burguesa como explicación de la vida, ante todo lo que signifique negación de lo instintivo, que en Nietzsche es negación de la vida, en último término.

Planteada la pregunta filosófica por la moral, tras ella se encuentra no sólo quien pregunta por la moral, sino además qué moral es la que persigue quien pregunta por ella, ya que para Nietzsche, toda postura moral sostenida por alguien es el resultado de sus propios instintos y de sus propias jerarquías (Nietzsche 2001). A dicha moral perseguida se le quiere imprimir en la naturaleza, como los viejos estoicos, y ejercer desde la filosofía moral de cada filósofo una forma de dominio, radicada no en la razón, sino en lo volitivo, lo cual es negado y desentendido. A la moral no se le pretende salir desde lo profundo del hombre $^{12}$ sobrepujando el temor y los prejuicios, sino que se pretende que sea un

\footnotetext{
${ }^{12}$ En este sentido habla de la psicología como ciencia principal en el estudios de estas relaciones, con lo cual, se adelanta, coincide o inspira los trabajos de Freud, todas estas alternativas discutidas y tenidas presentes, en los vínculos entre Nietzsche y Freud.
} 
instrumento de un adormecimiento de lo instintivo en el hombre, tal cual como el sabio de la cátedra de virtud de su "Así habló Zaratustra", el cual enseñaba adormecer el sentido de la vida (Nietzsche 1998:56). Hay aquí un círculo vicioso que Nietzsche nos quiere demostrar: la idea de lo moral que surge de lo instintivo para negar lo instintivo a través de la propia moral. Eso conduce a la creación de la mala conciencia por parte de los hombres de resentimiento. "La conciencia moral -según habla Fink sobre este punto de la filosofía de Nietzsche- no es otra cosa que un instinto de crueldad refrenado en su desahogo hacia fuera y que, por ello, se ha vuelto hacia dentro" (Fink 1966:191). Así nacen los prejuicios morales, y la clasificación de instintos buenos o malos, no obstante ser todos instintos del ser humano, sin sentimiento de bondad o maldad por ellos, antes de ser rotulados como tal. Son más bien interpretaciones morales de los fenómenos, formas de someter los instintos naturales del hombre, por ende una "tiranía contra la naturaleza" y contra la razón.

$\mathrm{Ni}$ aún la antigüedad clásica escapó de esta arremetida de la razón y del ahogo de lo instintivo, donde -según el filólogo alemán (Nietzsche 2000)- Sócrates y Eurípides son los artífices de una contestación y/o contramanifestación ideológica de lo instintivo y la embriaguez trágica: los ataques contra lo dionisiaco que, no obstante, se erguía en idéntica importancia a lo apolíneo y en oposición constante prodigando ambas una construcción recíproca del antiguo espíritu griego.

De ahí que sobrepuje en Nietzsche, la recuperación del espíritu dionisiaco del horizonte histórico, filosófico y vital de lo griego, contradicho por el socratismo moral, que no era más que el signo de la decadencia, del cansancio, del agotamiento, "del anarquismo disolvente de los instintos" (Nietzsche 2000:36). No es sólo una visión moral, ni estética, sino que aún se eleva en una cosmovisión que teñirá su pensamiento y sus escritos, y que se extenderá hasta señalar la posición del hombre en el mundo como "una cuerda tendida entre el animal y el superhombre" (Nietzsche 1998:31), y la formulación de aquel como un desarrollo final del espíritu.

Es por estos motivos que de igual manera se encuentre en oposición consciente al cristianismo y en específico y más bien, a la moral cristiana burguesa, siendo ésta blanco constante de sus críticas, ${ }^{13}$ al entender el pensador que el cristianismo niega los instintos, la sensualidad, y por ser calumniadores del presente con la búsqueda de un "más allá" y

\footnotetext{
${ }^{13}$ Es necesario precaver, en todo caso, que toda la crítica de Nietzsche, siempre se debe entender en un discurso positivo, aunque parezca lo contrario. Se le ha tildado de anticristiano y de inmoral, en el sentido burgués de la palabra. Sin embargo, a Nietzsche se le debe leer entre líneas (Al igual como él mismo proponía leer entre líneas a los filósofos (Nietzsche (2001) Más allá del bien y del mal, trans. Andrés Sanchez Pascual, Biblioteca de autor, bolsillo, Alianza Editorial, Madrid, p. 24). Utiliza un lenguaje provocativo, denostador. Pero se debe estar atento. Si se define "anticristiano", se define anticristiano respecto del cristianismo burgués, o bien, de las interpretaciones que de éste hace la visión burguesa; si se define "inmoral", es en relación a la formulación axiológica burguesa de su tiempo. Siendo así, su contraposición es necesariamente antitética, pero antitética de valores decadentes de su época. Por ende, es más moral, y por qué no decirlo, más "cristiano" que toda la base de la moral burguesa. Su contraposición es contra la eticidad establecida.
} 
mantener una constante "hostilidad a la vida". ${ }^{14}$ Así Zaratustra los señala: "Vosotros predicadores de la igualdad, la demencia tiránica de la impotencia es lo que en vosotros reclama a gritos "igualdad": ¡vuestra más secretas ansias tiránicas se disfrazan, pues, con palabras de virtud!" (Nietzsche 1998:160). Decanta esto en la construcción de un cuadro general axiológico de la sociedad burguesa europea de su tiempo, donde ésta, para el autor, niega los instintos, al punto de pretender anularlos.

\section{Pensamiento jurídico-penal en Nietzsche}

\section{La norma moral como fundamento de la norma penal ("nemotécnica del dolor")}

Nietzsche en forma crítica plantea que la sociedad trata de hacer que el hombre viva en una eticidad vinculada constantemente a obligaciones, a promesas, a deberes éticos en suma. Pero previamente necesita lograr la uniformidad del hombre, hacerlo "igual entre iguales". Con ese objetivo se establecen reglas o normas morales, para ajustar al hombre a estas reglas, y lograr la uniformidad e igualdad esperada (Nietzsche 2003). La uniformidad, la costumbre, entonces, se vuelve ética. El efecto que pretende producir estas normas éticas es el remordimiento y la culpa en el hombre, de tal modo de evitar la comisión de conductas o impedir su reiteración.

Pero no basta con crear normas éticas, ello porque el hombre posee a su vez una costumbre contraria: la de volver tras sus instintos, y con esto, olvidar las normas morales que esclavizan la conciencia, olvidar la culpa y el remordimiento. Para evitar esto, la sociedad hace uso de un medio que le impida al hombre olvidar la eticidad de la costumbre. Este medio es el dolor. Así se produce el fenómeno de la "nemotécnica del dolor". De ahí surge todo un aparato lleno de mecanismos nemotécnicos, para traer al presente siempre el pasado, "el más largo, el más hondo, el más duro..."(Nietzsche 2003:69), haciendo recordar al hombre sus promesas, sus deberes morales, su culpa y sus remordimientos. "Para que algo permanezca en la memoria -dice el filósofo- se lo graba a fuego; sólo lo que no cesa de doler permanece en la memoria" (ídem.). Así se le prodiga una memoria al hombre, pero no sin precio, "jamás sin sangre" (ídem.), para que permanezca indeleble la norma moral. ${ }^{15}$ Este es el peso del camello que relata Zaratustra, y al hombre esclavo de

\footnotetext{
${ }^{14}$ Nietzsche (2000) El origen de la tragedia, trans. Eduardo Ovejero Mauri, Colección Austral, Madrid, p. 43. ${ }^{15} \mathrm{O}$ como dice Foucault interpretando a Nietzsche, que para la imposición de obligaciones y derechos se elabora métodos que establecen marcas, gravando "recuerdos en las cosas y hasta en los cuerpos". (Foucault (1988) Nietzsche, la genealogía, la historia, trans. José Vázquez Pérez, Ediciones Pre-textos, Valencia, p. 39).
} 
deberes morales, el camello (Nietzsche 1998).

Uno de estos mecanismos de la nemotécnica del dolor, y que, por ende, realiza la moralidad en el hombre a través del dolor, son las leyes penales, que, entonces, silencian la verdadera naturaleza del hombre; "calla para mí toda naturaleza/cuando oigo el tictac de la ley y del reloj"(Nietzsche 2002:59). Para Nietzsche, la nemotécnica del dolor se manifiesta en el mecanismo de las leyes penales, y en especial en la pena, como una relación proporcional entre la intensidad de las penas y la memoria del hombre, puesto que mientras mayor es la capacidad de olvido de la moralidad en el hombre, y de la culpa y el remordimiento, mayor será la dureza de las penas. Las leyes penales son para el filósofo, por así decirlo, la inscripción y transcripción de la moral. ${ }^{16}$ El derecho penal se vuelve así, en un aparato inhibidor de los instintos, para ser constantemente recordados en su negación. Como tal, el derecho penal para Nietzsche sirve para hacer más vívida la conciencia de la culpa (moral). ${ }^{17}$

\section{Interpretación genealógica del pensamiento contractualista en relación con el derecho penal}

Sabemos que el pensamiento contractualista sobre el origen de la sociedad, supone que cada uno de los individuos se compromete y cede su libertad natural, por una social. ${ }^{18}$ Nietzsche establece su visión en relación a los verdaderos orígenes de la promesa contractualista o pacto social. Para el pensador alemán, el significado de empeñar la promesa contractualista, supone ser objeto de la nemotécnica o mnemónica del dolor. Por ello es que las técnicas de castigo y las penas en sí, como mnemónica del dolor, ${ }^{19}$ son un costo para vivir dentro de la sociedad, ${ }^{20}$ la cual pasa por tener por justas y naturales cuestiones pactadas socialmente y por antinaturales e injustas cuestiones prejurídicas y presociales (Puy 1966:72).

\footnotetext{
16 "Cuanto peor ha estado "de memoria" la humanidad, tanto más horroroso es siempre el aspecto que ofrecen sus usos, en particular la dureza de las leyes penales nos revela cuanto esfuerzo le costaba a la humanidad lograr la victoria contra la capacidad de olvido y mantener presentes, a estos instantáneos esclavos de los afectos y de la concupiscencia, unas cuantas exigencias primitivas de la convivencia social." (Ibíd. p 70).

${ }^{17}$ Rousseau señala: "Quien desafía a los remordimientos, no tarda en desafiar a los suplicios, castigo menos riguroso, menos continuo..." (Rousseau (2003) Discurso sobre economía política, trans. Eric Fontanals, Editorial Quadrata, Buenos Aires, p 43), con lo cual el ginebrino parece servirle de base afirmativa a la posición de Nietzsche.

18 "El hombre -dice Rousseau- pierde su libertad natural y el derecho ilimitado a todo cuanto desea y puede alcanzar, ganando en cambio la libertad civil y la propiedad de lo que posee" (Rousseau, Jean-Jacques, $E l$ Contrato Social, p 28).

19 "tales imágenes y procedimientos se acaban por retener en la memoria..." (Nietzsche (2003) Genealogía de la moral, trans. Anibal Froufe, Gradifco SRL, Buenos Aires, p 71).

20 “... uno ha dado su promesa con el fin de vivir entre las ventajas de la sociedad...” (Ibíd., p. 71).
} 
En conformidad a la teoría contractualita de la formación y existencia de la sociedad, en idéntica forma se expresa el binomio delito/pena como una relación regulada por normas contractuales. Así el 'perjuicio' (delito) del sujeto debe recibir un equivalente (dolor). Surge la promesa del deudor para restituir lo adeudado. De tal modo, en una sociedad contractualista, el delito es mirado como deuda, el derecho de castigar del Estado, como derecho del acreedor sobre el deudor; el castigo se ve como un acto indemnizatorio a la sociedad. Sin embargo, el delito no significa compensación en dinero, sino más bien, otorgar un "sentimiento de bienestar" por encontrarse la víctima en poder de "hacer el mal por el placer de hacerlo" (Nietzsche 2003:73) sobre el infractor, de encontrarse en la posición de soberano sobre el otro. ${ }^{21}$ "Por medio de la 'pena' infligida al deudor, -dice Nietzsche- el acreedor participa de un derecho de señores, por fin llega también él una vez a experimentar el exaltador sentimiento de serle lícito despreciar y maltratar a un ser como a un 'inferior' o, al menos, en el caso de que la auténtica potestad punitiva, la aplicación de la pena, haya pasado ya a la 'autoridad', el verlo despreciado y maltratado. La compensación consiste, pues, en una remisión y en un derecho de crueldad" (Nietzsche 2003:74). De ahí que la pena, para el filólogo, no es más que retribución.

Dentro de este contexto, el individuo que comete un delito, el cual antes de su acto infractor poseía todas las ventajas de vivir dentro de la sociedad, no es penalmente reprochado por el daño a la sociedad, sino porque ha infringido el pacto social, con lo cual se hace deudor porque no devuelve las ventajas otorgadas por la sociedad en el pacto (al responder con un delito a las ventajas sociales), sino además ha atentado contra el acreedor (la sociedad, el Estado). Así se desata la cólera del acreedor quien lo devuelve al "estado salvaje y sin ley" (Nietzsche 2003:82), expulsándolo del seno de la sociedad, y como tal, libre para descargar toda su crueldad. Así surge el derecho penal, como un derecho de guerra contra el infractor, cuestión reconocida ampliamente por el pensamiento ilustrado. ${ }^{22}$

\footnotetext{
${ }^{21}$ Esto de algún modo se relaciona con lo dicho por el penalista español Jiménez de Asúa, quien encuentra fundamento de la pena "en los sentimientos instintivos [léase deseo de venganza (Que según Jiménez de Asúa provocaría en quienes atestiguan el delito como cuerpo social, "el deseo de venganza, provocado por la indignación causada por el delito" [énfasis del autor], (Jiménez de Asúa (1950) Tratado de derecho penal. Vol. II, penal, Losada, Buenos Aires, p 15) que provoca todo delito" y "en la necesidad de dar a esos sentimientos satisfacción suficiente para restablecer la tranquilidad pública" (Jiménez de Asúa (1950) Tratado de derecho penal. Vol. II, penal, Losada, Buenos Aires, p 14). García-Pablos de Molina, al explicar la "psicología de la sociedad sancionadora" expone: "Castigamos para dar satisfacción a una necesidad social de sancionar, proyectando sobre la víctima propiciatoria del infractor sentimientos colectivos inconscientes de culpa y frustración" (García-Pablos de Molina (1988) Manual de criminología, introducción y teorías de la criminalidad, Editorial Espasa-Calpe Madrid, p. 409.)

${ }^{22}$ Sobre este punto Rousseau afirma: "Por otra parte, cualquier malhechor, atacando el derecho social, se hace por sus maldades rebelde y traidor a la patria; violando sus leyes deja de ser uno de sus miembros; y aun se puede decir que le hace la guerra. En tal caso la conservación del estado es incompatible con la suya; fuerza es que uno de los dos perezca; y cuando se hace morir al culpable, es menos como ciudadano que como enemigo. El proceso y la sentencia son las pruebas y la declaración de que ha roto el pacto social y de que por consiguiente ya no es un miembro del estado. Mas como ha sido reputado como tal, a lo menos por su residencia, se le debe excluir por medio del destierro como infractor del pacto, o por la muerte como enemigo público; pues semejante enemigo no es una persona moral, es un hombre, y en este caso el derecho de la guerra es de matar al vencido" (Rousseau, Jean-Jacques, El Contrato Social, p 43). En el mismo sentido va César Beccaria, cuando en su libro "Tratado sobre los Delitos y las penas" (1764) afirma: "No es, pues, la pena de muerte derecho, cuando tengo demostrado que no puede serlo: es sólo una guerra de la Nación contra
} 
La pena, dentro de la existencia del pacto social, es una forma de reacción idéntica al vencedor en contra del enemigo en una guerra, donde éste pierde todo derecho, protección y gracia, lo cual se demuestra en que la guerra, produjo todas las formas de penalidad conocidas (Nietzsche 2003:82). ${ }^{23}$ De ahí que quien comete un delito es considerado un enemigo de la ley y de la sociedad (Nietzsche 1969), un rebelde, ${ }^{24}$ un traidor, un violador del pacto y que, al haber cometido el delito estableciendo su guerra en contra de la sociedad, igualmente "se le combate con los medios que proporciona precisamente la guerra" (Nietzsche 2003:92).

Visto así el panorama, el contractualismo, sería una forma recubierta y enmascarada sobre las verdaderas razones de la penalidad, que la sociedad sostiene como fundamento, enmascaramiento que se refleja en dos cosas: a) En que el derecho penal sería una guerra reglamentada contra el individuo, ahora enemigo de la sociedad; b) Que se activan los mecanismos del derecho penal por el delito, no implicando este daño social, sino vulneración o infracción del pacto social. Ambos presupuestos nos lleva a desplazarnos hacia la pregunta de la pena, del cómo se relaciona la pena con este esquema, de sus razones y fundamentos, y de la función específica.

\section{Finalidades $y / o$ funciones de la pena}

El punto de partida para las siguientes distinciones en Nietzsche, serán las vertidas por Ferrajoli en relación a las discriminaciones en torno a la función y la finalidad de la pena, entendida en la primera como relativa más bien al ser y a la última en relación al deber ser del sistema punitivo (Ferrajoli 1989). Esta dualidad del sistema entre funciones y

un ciudadano, porque juzga útil o necesaria la destrucción de su ser." [énfasis suplido], (Beccaria (1945) Tratado de los delitos y de las penas, trans. Guillermo Cabanellas, Serie, Biblioteca Jurídica Atalaya, Buenos Aires, p 105).

${ }^{23}$ Aún piensa que en la actualidad no ha transformado su visión la sociedad sobre el respecto, al considerar la moderna creación del Estado como una "inmoralidad organizada", en referencia al derecho de guerra que significa el derecho penal (En "La voluntad de poderío", en Nietzsche (1969) Obras Inmortales, Ediciones Distribuciones, Madrid, trozo 713, p. 1508).

24 "A un rebelde no se le "castiga", se le somete". (En "La voluntad de poderío", en Ibíd., trozo 735, p. 1517) 
fines de la pena, es visto desde la genealogía nietzscheana con un prisma diverso, entendido fundamentalmente como que todo fin de la pena, y como tal, todo fundamento axiológico de la pena, se encuentra cimentado sobre las bases de la moral. No hay así, fines especialmente separados del derecho de la moral. Sin embargo, supone el pensamiento de Nietzsche que los fines del derecho son formas de encubrimiento sobre las verdaderas razones del derecho en establecer finalidades para la pena. Aparecen así, fines reales y fines aparentes.

En el comienzo del desarrollo del derecho penal, el delito era oprobioso, y por ende, la función de la pena fue eminentemente retributiva, motivada por la venganza, por la "cólera". La justicia penal, así, era una forma de "santificar la venganza"(Nietzsche 2003:83), y con ello quedaba definida su finalidad: satisfacer los deseos de venganza. Posteriormente, la pena logra un segundo momento, sin dejar el primero. Así para Nietzsche "con la pena se puede lograr (...) el aumento del temor, la intensificación de la inteligencia, el dominio de las concupiscencias: y así la pena domestica al hombre, pero no lo hace 'mejor'" (Nietzsche 2003:95) [énfasis suplido]. Aquí, fines y funciones del segundo momento de la pena se producen: a través del temor por medio de la intimidación por la pena, hace posible la nemotécnica del dolor y por ende, el recuerdo y la lucha contra el olvido. Esto trae como consecuencia, la domesticidad del hombre. Así entonces, la función es la intimidación, para conseguir el fin que es la represión del instinto.

En concordancia con lo señalado por Nietzsche es posible rastrear ambas finalidades desarrolladas en el seno de la sociedad burguesa, y fundamentadas teóricamente desde las bases de la Ilustración: tratándose del fin retributivo, Kant, y de la prevención, pensadores como Beccaria y Bentham. Así Kant, en la formulación de la finalidad retributiva de la pena, basa su fundamento en el ius talionis, como forma de proporcionar la pena al hecho y a su hechor (Kant 1989), en el fundamento que la ley penal es un imperativo categórico, negando de entrada cualquier finalidad preventiva, por no considerarse al ser humano como medio, cuestión que Feijóo Sánchez (2002) ve como pretensión de cortar con los excesos utilitaristas y preventivos de la Ilustración. Tal prevención a la que Kant pretendía oponerse, como señalaba el autor citado, es sostenida, entre otros por Beccaria, quien busca que la pena sea un motivo sensible que hiera los sentidos (Beccaria 2002:30-31) y que cause una impresión eficaz y durable, de tal modo, que a través de esto, impida al reo cometer más daños y al resto de los asociados los retraiga de su comisión (Beccaria 2002:51). En estas condiciones descritas por Beccaria, el fin es de prevención negativa, tanto especial como general. Para Bentham el fin sin duda alguna es la prevención, ${ }^{25}$ fase

\footnotetext{
25 "Antes de que un delito se consume, puede anunciarse de muchas maneras, y pasa por algunos grados de preparación que a veces permiten contenerlos antes de que llegue a su catástrofe” (Bentham (1842) Tratados de legislación civil y penal, trans. Baltasar Anduaga Espinosa, Madrid, p. 59).
} 
que él asume aún en contextos previos al delito, basado en la vigilancia policial y hasta ciudadana, y en las fases ya de comisión del delito, ${ }^{26}$ con sanciones de corte eminentemente preventivas, en búsqueda de la economía penal ${ }^{27}$ como fin (Bentham 1842). Su opción así, es mayormente por la prevención especial en materia penal.

Nietzsche así se encuentra en lo cierto al describir los dos paradigmas dominantes de los fines de la pena formulados durante el período ilustrado, y que se afincaron en el seno del pensamiento burgués. Pero aún más, critica los fundamentos de aquellos -aunque no haga alusiones tan directas como las hace Foucault luego-, al exponerlos como falseados, como desenraizados de sus verdaderos motivos, y por los cuales existen dichas funciones de la pena acogidas en el seno del derecho penal. "Mas -prorrumpe Zaratustra- yo os aconsejo así a vosotros, amigos míos: ¡desconfiad de todos aquellos en quienes es poderosa la tendencia a imponer castigos!'(Nietzsche 1998:161). La imposición de castigos supone una doble función moral e instintiva: satisfacer deseos de venganza que surgen más bien del resentimiento, o de volcar contra el infractor la cólera por un hecho envidiado en su factura por el resto, debido a la liberación de instinto. Si en un momento la retribución relaja la cólera a través de la pena y el instinto de venganza y del resentimiento, la pena como recordatorio, como regla nemotécnica punitiva, intimida, manteniendo fresca la memoria de las prescripciones morales para sojuzgar los instintos.

Así, y estableciendo una suerte de rótulos, para Nietzsche la pena en verdad cumpliría dos funciones: una función instintiva y una función utilitaria.

Como función instintiva, la pena satisface los deseos de venganza y de cólera de la sociedad en contra del infractor. Esta función de la pena, surge de sociedades históricamente primitivas, y subyacen idénticas funciones en la sociedad burguesa del resentimiento. Esta habría sido encubierta por la denominada finalidad retributiva de la pena.

Como función utilitaria la pena es un mecanismo que a su vez cuenta con dos subfunciones: a) como mecanismo de nemotécnica individual, que a través del dolor, al infligir la pena, tiene por función recordar al hombre su culpa (función nemotécnica especial); b) como mecanismo nemotécnico, tiene por función recordar al hombre su promesa contractualista, con el fin de la mantención del orden social (función nemotécnica general). En el binomio de la función/finalidad, la función/finalidad "máscara" con la que

\footnotetext{
26 “...hay otros [medios] que son propios únicamente a los magistrados y de que puede usarse con mucha utilidad para prevenir algunos delitos que se recele” (Ibíd., p. 60). Así señala, por ejemplo en la sanción de conminación que es aquella donde existe "la voz (...) de un magistrado que intimida con un lenguaje severo" [el resaltado es nuestro] (Ídem).

27 "nunca se debe usar de un medio preventivo de tal naturaleza, que haga mas mal que el delito mismo" (Ibíd., p. 61).
} 
la sociedad encubre el verdadero binomio, la función entonces sería la intimidación y la finalidad la llamada prevención.

\section{Sociedad, poder y derecho penal: su "más allá" del derecho penal}

Para Nietzsche, las sociedades en la medida que aumentan su poder (y en la historia igualmente), les resulta menos oprobioso el delito. En la medida en que el "poder y la autoconciencia de una comunidad crecen"(Nietzsche 2003:83), el derecho penal se ablanda; y si por el contrario, existe debilitamiento de aquella, se endurece éste. Al resultarle menos ofensivo el delito, la sociedad trata así de buscar formas de penalidad equivalente, formas indemnizatorias y de composición que remplacen la pena. ${ }^{28}$ Esto porque el acreedor es más poderoso, y "rico" también. "No sería impensable -acota el filósofo- una conciencia de poder de la sociedad en la que a ésta le fuese lícito permitirse el lujo más noble que para ella existe, dejar impunes a quienes la han dañado" (ídem). No por misericordia, sino por derroche de fuerzas la comunidad llega hasta a autosuprimir la justicia penal, convirtiéndose ésta en gracia (perdón). Este sería, "su más allá del derecho" (ídem).

Es por esta razón que una comunidad con una conciencia de poder y ejerciendo este poder, impone el derecho a otros, obligándolos "por la violencia a un compromiso" (Nietzsche 2003:85). Nietzsche ve como base la diferencia entre los hombres activos y reactivos. Estos últimos se ven justos, pero a la menor provocación reaccionan. Son hombres de resentimiento (pueblos de resentimiento, considerados los judíos y el cristianismo como sus paradigmas más próximos para Nietzsche $)^{29}$ que han creado la culpa y el remordimiento de la conciencia, creadores del derecho de guerra y de la venganza. "En cada una de sus quejas resuena la venganza ${ }^{30}$-según pregona Zaratustra-, en cada uno de sus elogios hay una agravio; y ser jueces les parece la bienaventuranza" (Nietzsche 1998:161). En cambio, los hombres activos, son agresivos y dotados de conciencia, libres y mejores. Son las comunidades activas las que necesitan más del derecho para imponerlo y frenar a los poderes reactivos, vengativos y destructivos, obligándoles al pacto social. El derecho es imposición de los más fuertes a los más débiles, con el fin de quitarles "de las manos de la venganza el objeto de resentimiento"(Nietzsche 2003:86). La comunidad, la "potestad suprema", al establecer la concepción del delito como "rebelión contra la

28 “...la voluntad, que aparece en forma cada vez más decidida, de considerar que todo delito es pagable en algún sentido..." (Nietzsche (2003) Genealogía de la moral, trans. Anibal Froufe, Gradifco SRL, Buenos Aires, p. 82)

${ }^{29}$ Cuestión controvertida por Julián Marías, donde el autor piensa que Nietzsche comprendió mal la filosofía cristiana lejana al resentimiento y su idea, que el filólogo sostenía (Marías (1965) Historia de la Filosofía, Manuales de la Revista de Occidente, Madrid, p. 357).

30 "El ejercicio del poder acarrea muchos disgustos y requiere mucho valor. Por eso hay tanta gente que no hace valer su derecho, porque este derecho es una especie de poder y son demasiado perezosos o demasiado cobardes para ejercerlo." (De "Humano demasiado humano", en Nietzsche (1969) Obras Inmortales, Ediciones Distribuciones, Madrid, trozo 251, p 1106). 
potestad suprema misma" (ídem.), y no como perjuicio contra un individuo de la sociedad o ante esta entera, ya no ve lo que es justo e injusto, por lo tanto ya no necesita de una valoración moral de los actos, sino que comienza a tener una "apreciación cada vez más impersonal de la acción". Esta comunidad es el Estado, pero no nace éste de un contrato social, el cual Nietzsche niega para la formación de las sociedades, (tratándola de "fantasía") sino de la voluntad de poder de una comunidad, libres, conquistadores, "organizados para la guerra, y dotados de la fuerza de organizar" (Nietzsche 2003:99). Nace, hasta cierto punto, de leones que se han despojado de su naturaleza de camellos y que han mutado hasta constituir un nuevo espíritu, libre, señor de su propio desierto (Nietzsche 1998).

Propone, entonces, un "programa" en la constitución del Estado y el desarrollo punitivo que se puede exponer en los siguientes ítems: a) Que el Estado surja por la voluntad individual reunida grupalmente y por mera tolerancia o aquiescencia tácita de sus individuos; b) El derecho penal debería ser monopolizado por los más fuertes, para evitar que se transforme en instrumento de venganza, así surgirían formas menos duras de respuestas penales pero no por humanidad, sino como dádiva de la sociedad, por derroche de fuerzas, por mera sobra de poder. Esto con la finalidad de recuperar la fuerza del hombre, restaurar su potencia, devolver la voluntad de poder, pero a través del Superhombre, de Dionisios, sin los cuales el poder sólo sería violencia en el mando (Ricoeur 1970).

Sobre este punto y para Puy (1966), el proyecto nietzscheano era el de armonizar la fuerza con la moralidad, o bien, la necesidad con la libertad, lo cual se expresa a su vez, en dos "antinomias" (Puy 1966:208) o "tensiones" (Puy 1966:206) entre fuerza jurídica directiva de la racionalidad y la fuerza jurídica coactiva de la sanción; entre libertad subjetiva y la jerarquía objetiva. La primera tensión se manifiesta en que para Nietzsche el derecho no puede concebirse sin fuerza, por ende, es necesaria la fuerza coactiva de la sanción. Pero para Nietzsche además existía un derecho vital, un derecho basado en la voluntad de poder, en la significación existencial humana como voluntad de vivir (y por ello Puy trae a colación la comparación nietzscheana de la ciudad sitiada, ${ }^{31}$ a la cual Puy atribuye el ser un derecho natural, mas al negar Nietzsche el derecho natural y al hablar en su lugar de vital "es un puro juego de palabras", ya que en el fondo se refiere a la naturaleza que para Nietzsche era la "esencia de la existencia humana" (Puy 1966:207).

La segunda tensión, la situación entre libertad (subjetiva) y la jerarquía (objetiva). Para resolver esta tensión, Puy recurre a la crítica de Nietzsche a la idea de la igualdad ante la ley. Nietzsche niega dicha igualdad debido a que los sujetos que componen la sociedad son desiguales por naturaleza, siendo su desigualdad lo que define su individualidad. Esta

\footnotetext{
${ }^{31}$ Ciudad que aún sitiada conserva su poder (Puy (1966) El Derecho y el Estado en Nietzsche, Jurídica, Científico, Editora Nacional, Madrid, p. 206)
} 
jerarquía y diferencia entre unos y otros, los “jerarquiza objetivamente" (Puy 1966:209) en la sociedad, de un modo no igualitario sino proporcional a dicha jerarquía. El reconocimiento jurídico de la jerarquía deviene en la libertad de cada individuo concreto dentro de cada jerarquía.

El derecho en Nietzsche así, y para Puy, es un "derecho natural basado en la concreta consideración del hombre y sociedad concretos" (Puy 1966:211).

De cierto modo, este que es su "más allá del derecho penal" supone que existe en Nietzsche una forma dialéctica de proponer la genealogía de la historia de la penalidad, que en un primer momento, si bien es netamente hermenéutica y expositiva, pasa a ser luego dialéctica positiva y propositiva. ${ }^{32} \mathrm{Su}$ pensamiento evidencia en forma indudable, una contradicción entre los instintos y la moral, y por ende, entre la moral y las leyes penales. Esto debido a que la moral y las leyes penales niegan los instintos, estableciendo, una relación de contrariedad, de oposición. Esto presenta, si interpretamos correctamente su filosofía en general, un momento dialéctico, que Nietzsche habría de hallar en el Superhombre la resolución de este momento dialéctico. Esta resolución no sería más que una de las formas del vitalismo que enunciaba Nietzsche, y que no es más que la particularización de la situación general de la forma positiva de superación del momento dialéctico.

\section{Interpretación político criminal y dogmático penal de la fórmula nietzscheana}

De acuerdo al prisma nietzscheano, que podemos interpretar de acuerdo al paradigma de la ciencia penal (sobre todo desde la visión del funcionalismo moderado), existen diversas observaciones del pensador alemán que podríamos sistematizar de acuerdo a dicha paradigmática. En principio, los problemas del ataque del pensador, sin duda son finalmente una crítica a la política criminal del Estado burgués europeo, crítica que por cierto se establece como una genealogía y que, por ende, tiene por objeto descubrir el origen y lo subyacente, lo que se encuentre oculto tras el velo de la discursiva tradicionalmente sostenida en forma oficial.

Efectuando una interpretación y sistematización penal en Nietzsche, para quien las razones político-criminales tienen un contenido valorativo pero fundamentalmente ético, y que en virtud de dichas valoraciones se establecen las directrices que determinan los

\footnotetext{
${ }^{32}$ Y este sentido y al igual que las visión de Deleuze sobre Nietzsche (Vid. Deleuze (1986) Nietzsche y la filosofía, trans. Carmen Artal, Editorial Anagrama, Barcelona), se rechaza la opción dialéctica en el sentido hegeliano, es decir una dialéctica de la negación en el filólogo, cuestión esta última que también arribó como conclusión Dussel de la dialéctica de Hegel.
} 
aspectos dogmáticos, en especial, las delimitaciones en relación al delito y la pena. Así los valores éticos (valoración ética burguesa europea del tiempo del pensador, lo cual es bueno dejar claro), "orientan" la valoración político criminal. De acuerdo a ello, es posible fijar las conductas que serán objeto de recogimiento típico. En segundo lugar, hasta cierto punto la "finalidad" subyacente y "verdadera", que se encuentra impresa en dicha política criminal, es posible reconocerla en la uniformidad que pretende lograr de los regidos por las normas, y consecuencialmente, en la subyugación de éstos, o si se quiere, el fin normativo sería la estandarización de los ciudadanos regidos por la norma, y el fin sistémico, la subyugación. Subyugación, por cierto, entendida en el sometimiento de los instintos que haría del hombre libre en su existencia. Así el derecho penal se vuelve un instrumento de poder frente a la existencia libre del hombre. De ahí que la observación de Nietzsche sobre la uniformidad o estandarización sea considerada por Puy como la crítica más importante de Nietzsche en el campo penal (Puy 1966).

Las consideraciones dogmáticas sobre este punto son evidentes en el objetivo de la política criminal burguesa: consagrar tipos penales que establezcan conductas que sean moralmente repulsivas para una sociedad $\mathrm{y}$, consecuencialmente, recordatorios al hombre de la culpa moral que puede originarse al trasgredir la norma. Pero es necesario además representar dicha conducta como lesiva a esta sociedad, plantear la conducta como un acto en contra del soberano: en contra de la uniformidad misma que es el soberano. La culpabilidad así (en el sentido más primitivo de la teoría general del delito), vendría a adicionarse a este esquema burgués, al significar el reproche personal al sujeto por el acto cometido, reproche que en el esquema nietzscheano es moral y penal. Y con la idea de culpabilidad, aún establecemos el cierre del sistema al atribuir la verdadera sede a la cual la norma penal pretende regir: la conciencia moral. Esto sería configurar una teoría del delito que encubriera las verdaderas razones de su consagración: la aspiración de la sociedad de atentar contra la "liberación" de la existencia humana.

Si a ello agregamos las finalidades de la pena descritas por Nietzsche, el esquema se hace más completo. Si seguimos el principio genealogista, el verdadero fin de la pena sería la retribución en sus términos más rudos, o sea, la venganza; y como segunda finalidad, la preventiva negativa, es decir, la intimidación. Nietzsche pareciera observar esta última en las descripciones legales de quienes determinan una pena imputada a la conducta, intimidación como infracción del carácter vital del individuo, porque es negación de la vida (Puy 1966); esto, por la amenaza del castigo, como un recordatorio más poderoso de la culpa moral por la posible trasgresión de la conducta prohibida. Aquí cobra importancia la moralidad como supuesto del sistema penal, ya que aquella permite abrir los ojos al bien y el mal, el abrir los ojos ante las prohibiciones éticas de la tradición burguesa, de las reglas morales y sus conductas consideradas "malas", "pecadoras". Ya sobre este nicho de moralidad se sitúa el derecho pena sobre un terreno conocido, sobre el terreno donde los ojos ya han sido abiertos por la moral, para establecer a través de las reglas criminales, la 
penalidad para recordar de forma más vívida al hombre -porque es amenaza de caer sobre sí todo el peso del soberano a través de la venganza reglamentada- sus obligaciones morales. En suma: nemotécnica (pena como intimidación) del dolor (remordimiento/culpa moral). De delinquir el hombre, la culpabilidad penal se vuelve sin duda, un recordatorio indeleble de la culpa moral, una marca en la carne puesta por el soberano al súbdito para rememorarle, con el fierro candente de la pena, su culpa, y -como dijera Foucault (2002)su pertenencia al soberano, unido a él por el pacto social.

Ahora bien, sin duda que lo descrito ha de interpretarse como de lege lata para el filósofo. Pero de lege ferenda, su observación pretende objetivos que podría pensarse ajenas a alguna proposición de éste, por su aparente postura crítica apropositiva y la sensación de ser concebido como negador de cualquier idea de derecho. Esta proposición es magistralmente ilustrada por Puy, al señalar que Nietzsche lo que ataca es la abstracción jurídica, pero que persigue en los legisladores la búsqueda de la concreción, en "existencias humanas concretas", a "no confundir (...) hombres o situaciones, que pueden ser semejantes, pero nunca idénticas" (Puy 1966:83). La crítica sobre esta observación puede estar dirigida sobre la necesaria y justificable abstracción que efectúa el legislador en las descripciones típicas, y la delegación de la tarea concretizadora en el juez que hace el sistema jurídico-penal. Sin embargo, pareciera ser esto menos obvio si nos compadecemos del verdadero sentido de las afirmaciones expuestas. En el fondo se persigue la conformación de tipos penales que no prediquen en relación a prescripciones netamente morales y dirigidas con la finalidad de subyugar. Al perder de vista la moralidad como centro de atención de la norma penal, el derecho criminal rehuiría la estandarización de la conducta, con lo cual reflotan las particularidades: la existencia concreta del ser humano.

\section{La fórmula nietzscheana y su relación con Latinoamérica}

La visión nietzscheana sobre la historia de la penalidad, proporciona una serie de cuestiones a considerar tras una óptica de lo latinoamericano. Esto no es en específico, un predicamento que desde lo europeo deba dimanar hacia Latinoamérica, cuestión constante en los pensadores eurocentristas. Nuestro aserto se funda en dos apreciaciones.

En primer lugar, Nietzsche se plantea como crítico de la sociedad burguesa europea de su época, y de algún modo y casi equivalente, a la sociedad dominante. La actualidad del pensamiento de Nietzsche no ha dejado de cesar, pese a, supuestamente, encontrarnos en otra clase de época. Esto nos lleva a pensar en que si las críticas no habrían de perder actualidad, entonces tampoco la habrían de perder los modelos que Nietzsche describía genealógicamente. Ahora bien, la crítica de Nietzsche es crítica de un europeo hacia la sociedad europea. De algún modo, Nietzsche al igual que muchos de los llamados "filósofos de la sospecha", develan la mala conciencia de Europa (o su buena conciencia). 
Describen la verdadera intención, lo que existe bajo el tejido, bajo la maraña de formas impuestas, el por qué de las formas y de su imposición. Esto es un negativo dagerrotípico para Latinoamérica. Se puede determinar con mejor precisión el pensamiento europeo, con sus bondades y bemoles, con sus verdades y mentiras. Eso nos lleva, por exclusión y de forma negativa, a establecer planos comparativos que determinen qué queda de residuo ideológico para Latinoamérica, si consideramos que hemos sido forjados como europeos menores, basados en sus sistemas de pensamiento. A lo menos, podemos precisar el cuadro completo (o comenzar a reconstruirlo), en fijar el pensamiento europeo en toda su extensión, para entender qué tanto de este constructo hemos derivados nuestras categorías, nuestras formas de ver el mundo, nuestro episteme, en último caso. Europa no ha dejado de traspasar nuestras visiones de mundo, quiérase o no. Si a lo menos podemos precisarlo, se podrá establecer qué tan traspasados de lo europeo hemos sido.

En segundo lugar, la genealogía es un instrumento útil para desembarazar la maraña que históricamente se ha petrificado en Latinoamérica. Habiéndose adherido el pensamiento europeo a Latinoamérica, por elección o por fuerza -mejor dicho por la razón o la fuerza-, siendo la genealogía una herramienta elaborada en razón de dicho pensamiento europeo, a su molde y estructura -y que como herramienta, entonces útil en la crítica histórico filosófica europea-, es útil y adecuada también para desenmarañar las construcciones históricas latinoamericanas entramadas con el hilo de lo europeo. ${ }^{33}$

Centrándonos en la historia de la penalidad, que es lo que nos convoca en el hoy, la crítica nietzscheana no deja de tener contemporaneidad en su discurso en los derroteros latinoamericanos en su historia penal, de considerar sólo, verbigracia, la serie de normas penales que se orientan en algunos códigos hacia cuestiones morales, o que habiendo militado dentro del catálogo de delitos, fueron abandonados no hace mucho. En el hoy, si bien tratadas como algo vergonzoso, en boga están las disposiciones que se basan en la seguridad ciudadana, concepto que ha atendido en extender o expandir en palabras de Silva Sánchez (2001), las conductas de peligro o de un "derecho penal del enemigo", planteadas como una nueva forma de moralidad e inmoralidad, pese al "daño" a la sociedad que parecen significar, que en todo caso, aún son sospechosas tanto en cuanto a su origen como en su etiquetamiento desde los centros de poder. El derecho penal deja sus fuentes lógicas y objetivas (aún puesta esta entre paréntesis como afirma Humberto Maturana) para ser más bien un derecho retórico, basado en la proclama y en la persuasión de los discursos y las problemáticas sociales, éstas últimas basadas en el miedo y la inseguridad, las cuales pueden ser ficticias para generar la necesidad de protección y de más derecho penal. Una nueva forma de "moralina" se posesiona como reformulación de los modelos de esclavitud señalados por Nietzsche.

${ }^{33}$ Este punto daría lugar, por su extensión, a un estudio posterior y más focalizado. 
Sobre lo último dicho, cabe apreciar la propuesta filosófico-penal de Nietzsche, que es de algún modo axiológica hacia lo ontológico, o si se quiere, las bases sobre las cuales parte para la superación de los esquemas burgueses es la liberación axiológica del hombre, la cual conduce finalmente a una liberación ontológica.

Si observamos la realidad latinoamericana, tal vez las posibilidades liberadoras en el sentido nietzscheano no hayan de situarse precisamente en aspectos puramente ónticos, ni puramente axiológicos. En efecto, el componente social es muy poderoso a la hora de aproximarse a las fronteras de lo latinoamericano. ${ }^{34}$ Sobre lo dicho, el tema de la libertad humana en un contexto determinado y concreto, que es social fundamentalmente, juega un especial papel en nuestra realidad. No es la libertad burguesa e ilustrada la que acude como centro de definición para la libertad latinoamericana, sino una libertad diferente, relacionada con cadenas sociales y políticas, arraigadas fuertemente y jalonadas por los centros de poder cada vez que se pretenda sacudirlas. Penalmente hablando, si el derecho penal ha de contribuir en esta concreción y liberalización del hombre latinoamericano, muchas son las consideraciones que deben existir a la hora de analizar el tramado de la penalidad. Por ejemplo, se debe abjurar de la idea de Quételet del hombre medio, trasvasada al derecho penal que aún, a nivel general y en un contexto europeo, es una concepción que siendo estadística, es ajena al hombre concreto, de carne y hueso. Para Latinoamérica resulta aún más absurda, si se consideran realidades diversas manifestadas en la multiculturalidad y la diversidad étnica. Otra de las cuestiones, ya a nivel de derecho penal especial, es que las disposiciones criminales no pueden penalizar, tan fuertemente el hurto ni el robo, disponiendo de sanciones alternativas para ello diferentes a la privación de libertad, que fuesen no sólo reparatorias a la víctima, sino donde esta misma participe de su aplicación alternativa.

Todo lo anterior se cierne como cuestiones básicas e incipientes dentro del campo dogmático, donde se puede explorar y encontrar un mundo de detalles contradictorios, dentro de un marco latinoamericano, que daría lugar a un estudio algo más profundo. Sí una cuestión que arrecia a nuestro continente desde un punto de vista más macro, son las descripciones teóricas del funcionalismo extremo de Günther Jakobs, y la fórmula del "derecho penal del enemigo", las cuales han hundido sus raíces en los desvelos penales de algunos iuspenalistas latinoamericanos, como es el caso paradigmático de Colombia. Esto, para una visión aguda pero horizontal, implica la aplicación de un modelo completamente ajeno en realidad, puesto que un sistema concebido dentro de la problemática europea y alemana en explicación de un modelo social, como es la teoría de sistemas -con su portavoz insigne como lo es Luhmann-, se encuentra alejado de la realidad latinoamericana. Sin embargo, si ha de aparecer este panorama como una mera apariencia, bajo esta falsedad

\footnotetext{
${ }^{34}$ Sin que esto signifique necesariamente situarse dentro del campo de lo identitario, problema que requiere aún un segundo aire de mayor precisión.
} 
llamada "verdad", hemos de encontrar una conformidad y aceptación de dicho modelo por los centros de poder, puesto que al ser modelos descriptivos se convierten en acríticos, y como acríticos y por su sola condición de acríticos, se transforman en legitimadores. Esto es de riesgo máximo si se trata del derecho penal, y sobre todo de las derivaciones teóricas del funcionalismo extremo de Jakobs en el derecho penal del enemigo, donde -y como ha sido expuesto (y podríamos decir demostrado) magistralmente por Demetrio Crespo (2005)- dicha descripción podría perfectamente devenir en fundamentación y justificación del estado de cosas descrito: un régimen penal diverso para el considerado enemigo (y que más aún, y con la hipótesis de constituirse dichos enemigos en generados por el propio sistema, o bien, falsificados para justificar decisiones políticas, el rótulo de enemigo no es ni siquiera tendencioso, sino derechamente falso). Y esto último es obvio si se piensa que el oficio del penalista no es sólo describir, sino también proponer; no es sólo establecer relaciones fácticas, sino axiológicas. Si se piensa de modo contrario, las puertas hacia las ciencias sociales están abiertas para hacer oficio, pero se cierran las jurídico-penales.

\section{Conclusión}

Pese a su interesante visión de sus formas propositivas de la sociedad, el Estado y el derecho penal, pueden existir deformaciones a la propuesta filosófica de Nietzsche -como respecto de todo su pensamiento-, sobre todo si el filósofo habla de una sociedad fundada en la voluntad de poder y en el derroche de fuerzas. De aquí surgen nuevos malos entendidos, como cuando Bodenheimer alude una supuesta paternidad nietzscheana sobre el nacionalsocialismo alemán, no en cuanto inmediata vía de constituir "una filosofía del Derecho sino como una filosofía de la política de poder" (Bodenheimer 2000:286). De ahí, tal vez, los resquemores, dudas y suspicacias con la visión sobre el derecho penal de Nietzsche. Sin embargo, la búsqueda del nacionalsocialismo alemán en el derecho penal, sostenida por la Escuela de Kiel, al haber basado su discurso en la irracionalidad penal (Bustos Ramírez 1989) y en la indeterminación legal, y a los derechos penal de la voluntad y del tipo de autor que Ferrajoli llama "moderno oscurantismo penal" (Ferrajoli 1989:42), nunca fue planteado en estos términos por Nietzsche. Las segregaciones raciales no se condecían ni en un ápice sobre el "sí a la vida" del filólogo, e iban mejor conducidas a una moral del resentimiento, cuestión que Nietzsche aborrecía.

De Nietzsche recogemos, sobre todo, la importancia de su interpretación de la interpretación, como guías hermenéuticas en la historia del derecho, y su posición interpretativa y sospechosa del contractualismo y del derecho penal, visión que fuera de no ser oficial, es una importante contribución a la racional desacralización de las motivaciones del derecho penal de los sistemas burgueses europeos, estableciendo nuevos bríos para la filosofía penal, y las visiones posteriores sobre el problema criminal, como las indagaciones posteriores que Foucault prodigare luego. 
Representa además, y ya a nivel general, una de las formas de precisión del perfil completo del pensamiento europeo, no con lo mejor y más noble con lo que aquel se ha hecho representar, como idearios sólidos, sin fracturas, quiebres ni disfraces, sino en su forma más real, más desnuda y descarnada, con sus apariencias y escondrijos, con sus recovecos y fachadas. Esto es de vital importancia para el pensamiento latinoamericano $-\mathrm{y}$ para el derecho latinoamericano-, ya que de la correcta definición del pensamiento europeo, se pueden zanjar nuestras similitudes y diferencias con aquel, en una reflexión negativa, de vernos sobre el espejo en lo más prístino, nítido, visible, no para esperar asemejarnos más a la imagen del espejo, sino para evitar toda semejanza con ella. En suma: antes que nuestra identidad como centro de desvelos, mejor comenzar con nuestra "desidentidad". 


\section{Bibliografía}

Beccaria, C. (2002) De los delitos y de las penas, trans. Juan Antonio de las Casas, Ciencias Sociales, E. 1. d. bolsillo, Alianza Editorial, Madrid.

Beccaria, M. d. (1945) Tratado de los delitos y de las penas, trans. Guillermo Cabanellas, P. Serie, Biblioteca Jurídica Atalaya, Buenos Aires.

Bentham, J. (1842) Tratados de legislación civil y penal, trans. Baltasar Anduaga Espinosa, Madrid.

Bodenheimer, E. (2000) Teoría del derecho, trans. Vicente Herrero. Vol. 60, Colección Popular, Fondo de Cultura económica, México.

Bustos Ramírez, J. (1989) Manual de Derecho Penal, Editorial Ariel S.A., Barcelona, España.

Carrasco Jiménez, E. (2008) «El pensamiento penal de Michel Foucault» Revista Polis, 18-05-2008, 18, Santiago de Chile, 223-239 [Disponible on line: http://www.revistapolis.cl/18/pens.htm].

Deleuze, G. (1986) Nietzsche y la filosofía, trans. Carmen Artal, Editorial Anagrama, Barcelona.

Demetrio Crespo, E. (2005) «El «Derecho Penal del enemigo» (Darf nicht sein!): sobre la ilegitimidad del llamado «derecho penal del enemigo» y la idea de seguridad» Revista General de Derecho Penal, $\mathrm{N}^{\circ}$ 4, [Disponible on line: http://www.zis-online.com/dat/artikel/2006_9_67.pdf].

Dussel, E. (1998) Ética de la liberación (en la edad de la globalización y de la exclusión), Colección estructuras y procesos, Filosofía, Editorial Trotta, Madrid.

Feijóo Sánchez, B. (2002) «Las teorías clásicas de la pena» Revista Peruana de Ciencias penales, Año VII-VIII, Septiembre, $N^{\circ}$ 11, Idemsa, Lima, 331-455, [Disponible on.

Ferrajoli, L. (1989) Derecho y Razón, Teoría del garantismo Penal, trans. Perfecto Andrés Ibáñez et al, Serie Derecho, C. E. y. Proceso, Editorial Trotta, S.A., Madrid.

Fink, E. (1966) La filosofía de Nietzsche, S. Humanidades, Madrid.

Foucault, M. (1988) Nietzsche, la genealogía, la historia, trans. José Vázquez Pérez, Ediciones Pre-textos, Valencia. 
Foucault, M. (1992) Genealogía del racismo, trans. Alfredo Tzveibel, Caronte Ensayos, Editorial Altamira, Buenos Aires.

Foucault, M. (1995) Nietzsche, Freud y Marx, trans. Carlos Rincón, Ediciones "El cielo por Asalto", Buenos Aires.

Foucault, M. (2002) Vigilar y castigar, trans. Aurelio Garzón del Camino, Siglo XXI editores, Buenos Aires.

Gandolfo, J. (1998) «Escritos políticos de Friedrich W. Nietzsche», en Estudios Públicos, Centros de Estudios Públicos, Santiago de Chile.

García-Pablos de Molina, A. (1988) Manual de criminología, introducción y teorías de la criminalidad, Editorial Espasa-Calpe Madrid.

Jiménez de Asúa, L. (1950) Tratado de derecho penal. Vol. II, F. y. 1. penal, Losada, Buenos Aires.

Kant, I. (1989) La metafísica de las costumbres, trans. Adela Cortina Orts y Jesús Conill Sánchez, Tecnos, Madrid.

Mann, T. (2000) Shopenhauer, Nietzsche y Freud, trans. Andrés Sanchez Pascual, Alianza Editorial, Madrid.

Marías, J. (1965) Historia de la Filosofía, Manuales de la Revista de Occidente, Madrid.

Moraleja, A. (2001), "Introducción," en A. c. Moraleja, Nietzsche y la "gran política”, 9-26, Madrid

Nietzsche, F. (1969) Obras Inmortales, Ediciones Distribuciones, Madrid.

Nietzsche, F. (1989) Correspondencia, trans. Felipe González Vicen, Ediciones Aguilar, Barcelona.

Nietzsche, F. (1998) Así habló Zaratustra, trans. Andrés Sánchez Pascual, Alianza Editorial, Madrid.

Nietzsche, F. (1999) El nacimiento de la tragedia.

Nietzsche, F. (2000) El origen de la tragedia, trans. Eduardo Ovejero Mauri, Colección Austral, Madrid.

Nietzsche, F. (2001) Más allá del bien y del mal, trans. Andrés Sánchez Pascual, Biblioteca de autor, E. 1. d. bolsillo, Alianza Editorial, Madrid. 
Nietzsche, F. (2002) La gaya ciencia, trans. José Mardomingo Sierra, 273 vols., Bilbioteca Edaf, Madrid.

Nietzsche, F. (2003) Genealogía de la moral, trans. Anibal Froufe, Gradifco SRL, Buenos Aires.

Nietzsche, F. (2004) Sobre verdad y mentira, Editorial Tecnos, Madrid.

Nietzsche, F. (2006) Nihilismo: Escritos póstumos, trans. Gonçal Mayos Solsona, Ediciones Península, Barcelona.

Puy, F. (1966) El Derecho y el Estado en Nietzsche, Jurídica, M. Científico, Editora Nacional, Madrid.

Quintano Ripollés, A. (1957) "Ideas jurídicas de Nietzsche", en Anuario de Filosofía del Derecho, 175-194.

Ricoeur, P. (1970) Freud: una interpretación de la cultura, trans. Armando Suárez, Siglo XXI Editores, México D.F.

Rousseau, J. J. (1988) El contrato social o principios de derecho político, trans. Villaverde, Editorial Tecnos, Madrid.

Rousseau, J. J. (2003) Discurso sobre economía política, trans. Eric Fontanals, Editorial Quadrata, Buenos Aires.

Silva Sánchez, J.-M. (2001) La expansión del derecho penal. Aspectos de la política criminal en las sociedades postindustriales, Civitas, Madrid.

Vattimo, G. (1989) El sujeto y la máscara, trans. Jorge Binagui, Historia, ciencia y sociedad, Ediciones Península, Barcelona. 